\section{Padre Jesuíno do Monte Carmelo: A Construção Barroca da Urbe Colonial (São Paulo 1774 - 1819)}

A minha motivação política é conhecer melhor os processos de ocidentalização, aculturação ou processo "civilizatório" que a cultura indígena enfrentou quando teve contato com os religiosos europeus durante o período colonial na cidade de São Paulo, em fins do século XVIII. A nossa investigação também vai buscar entender a cultura barroca dessa cidade e capitania. $O$ barroco foi um estilo artístico permeado por decisões políticas que influenciaram as ações de expansão urbana da cidade de São Paulo e manutenção de uma cultura cristã diante da sociedade colonial'.

Ao longo de muitos anos, a história dos índios foi escamoteada, o Estado nacional brasileiro negou a memória dos povos nativos. Em várias regiões do Brasil existe a ideia de que no Nordeste, no Sul e no Sudeste não restariam resquícios de comunidades ou cultura indígena, onde suas manifestações culturais teriam desaparecido, ou seja, a lógica popular acredita que essas comunidades estariam vivendo reservadas e resistindo apenas na região Norte do Brasil.

Essas afirmações são enganosas. Nos últimos anos, com a popularização dos Programas de Pós-Graduação em História em todo o Brasil, muitas pesquisas historiográficas investigaram o passado colonial, imperial e republicano do Brasil e acabaram problematizando as várias contribuições da cultura nativa para a vida social do país. Os historiadores, motivados por perguntas do presente, renovaram os debates sobre a história da participação dos indígenas na construção do Brasil. Cai num grande erro menosprezar a participação da cultura indígena na nossa formação nacional.

Outro sentido político e de poder muito presente na minha pesquisa são as imagens barrocas. A operacionalização da educação religiosa

1 O livro "Imagem e persuasão", de Giulio Carlo Argan, torna-se uma referência importante para que possamos entender a cultura barroca como uma cultura política ampla e presente no espaço urbano. Não podemos simplificar o barroco como mera arte, mas, sim, arte calculada/articulada e retórica, que tinha o poder prático, político, artístico, religioso e educacional. Para saber mais, ler ARGAN, Giulio Carlo. Imagem e persuasão: ensaios sobre o barroco. Org. de Bruno Contardi. Trad. de Maurício Santana Dias. Rev. de de Lorenzo Mammì. São Paulo: Cia. das Letras, 2004.
Me. Francisco Isaac

D. de Oliveira

Mestre em História pela UFRN e Doutorando em História Social pela PUC-SP. 
que os padres de várias ordens religiosas implantaram na catequese dos índios impuseram uma ocidentalização à cultura nativa e fizeram dos índios aldeados agentes receptivos do cristianismo, isso dentro de um contexto da Contrarreforma protestante. Dentro dessa perspectiva, o barroco também construiu espaços, irradiou poder e participou ativamente das decisões políticas tanto na corte portuguesa quanto na administração local.

Os religiosos sabiam do poder das imagens. Desde a Idade Média a igreja Católica utilizava-se amplamente da arte para educar e ensinar a fé cristã aos povos não cristianizados da Europa; todos os templos católicos na Europa dispunham de amplas coleções de arte que, dispostas nos altares e nas paredes dos templos, ensinavam quem eram as figuras centrais do cristianismo (Jesus, Maria e os santos), foi assim durante todo o período da arte gótica, no Renascimento e Barroco. A arte se converte num poderoso mecanismo de poder/saber, no qual as pinturas e esculturas narravam a vida de Jesus e dos santos, ensinavam sobre comportamentos e como ser um cristão bem-aventurado.

Detentores desse conhecimento, os franciscanos e jesuítas "transplantam" essa tecnologia para a América espanhola e portuguesa, dessa forma, vão criar uma cultura com suas apropriações, adaptações, construção e reconstrução dos significados das imagens e da arte religiosa; esse era o processo de ocidentalização de uma terra em construção.

A historiografia contemporânea brasileira tem, nos últimos anos, se debruçado e buscado problematizar as fontes do período colonial da América portuguesa a partir de uma perspectiva da história cultural. Muitos historiadores estudaram as relações dos colonizadores portugueses com o espaço social escravocrata (europeus, índios e negros africanos), buscando compreender o corpo social em sua dinâmica cultural, política e econômica, analisaram a influência da igreja Católica na vida dos nativos (indígenas) e colonos (europeus e africanos). Pensaram o Barroco como arte resistente que ajudou a barrar o crescimento protestante no Ocidente, esse é o contexto da contrarreforma católica. Várias são as abordagens de temas e perspectivas de estudos e análises. Atualmente, as discussões são relevantes e trazem da "escuridão" questões historiográficas que nos auxiliam no entendimento da história colonial.

Podemos identificar como linhas historiográficas mais estudas pelos historiadores brasileiros uma história que se preocupava com a escravidão, a expansão das terras pelos bandeirantes e uma gama de trabalhos feitos na tentativa de mostrar as relações econômicas entre a colônia e a metrópole, os ciclos econômicos do açúcar no Nordeste e do ouro no Centro-Sul (Goiás e Minas Gerais).

A nossa pesquisa vai analisar o período colonial pela ótica da arte e da política barroca. Vamos buscar suporte nos estudos das imagens e nos referenciarmos numa documentação imagética/pictórica ${ }^{2}$ que conte a história da educação/ocidentalização que os padres colocaram em prática num "projeto civilizatório", ou mesmo, uma política de resistência, pois era necessário que a fé cristã Católica sobrevivesse em outras terras além da Europa. A partir de duas séries de retratos - 10, no total - realizadas pelo Padre Jesuíno do Monte Carmelo e conservadas no Museu de Arte Sacra de São Paulo, vamos pesquisar e buscar entender como o barroco de fins do século XVIII vai contribuir para a construção da cidade de São Paulo.

Sendo assim, a complexidade social no período colonial da América portuguesa, forjou os espaços sociais do Brasil. Historiadores e sociólogos buscam entender e conhecer a história da América portuguesa por meio da arte e suas problemáticas na construção da história, da cultura, do pensamento social e da história da educação. Pretendemos dialogar com especialistas que discutiram e discutem a arte religiosa, o barroco, a cidade e o espaço. Entendemos que essas imagens tinham como finalidade educar, formando um espaço social diverso, onde os religiosos e índios, com suas tensões e aproximações, começaram a formar uma cidade.

2 Fontes visuais (pinturas e esculturas), cartas, fontes impressas, textos de referência sobre o assunto proposto para montarmos nossa pesquisa. 
O período colonial tem chamado a atenção de inúmeros historiadores, ao longo do tempo, várias teses e dissertações têm problematizado esse recorte temporal, mas, segundo a pesquisadora em História da Educação Thais Nívia de L. e Fonseca:

Nas obras analíticas sobre a historiografia brasileira de uma forma geral, o período colonial tem sido particularmente privilegiado, sobretudo quando se fala em novos temas e novas abordagens e, neste sentido, não se pode deixar de mencionar a influência de determinadas vertentes, sobretudo daquela denominada de Nova História e à qual está identificada a mais recente História Cultural, campo no qual têm sido feitas algumas das mais expressivas pesquisas sobre a história colonial. Privilegiado pela historiografia brasileira de uma forma geral, o período colonial não tem, contudo, despertado muito interesse nos historiadores da educação há várias décadas, ao contrário do que ocorre com o Império e o período republicano. (FONSECA, 2009, p. 112)

A professora Thais Nivia relata a falta de interesse dos pesquisadores da história da educação pelo período colonial; a maior parte dos pesquisadores prefere estudar a educação no período do Império e da República. A minha pesquisa identifica-se no campo da história cultural $^{3}$ e buscará problematizar a história da América portuguesa por meio da arte barroca. Acreditamos que as imagens barrocas são reveladoras para entendermos a história cultural e história social na colônia tanto por vias da catequese quanto pela construção dos espaços urbanos da São Paulo colonial.

Este trabalho objetiva estudar e problematizar a iconografia religiosa barroca usada com a finalidade de educar na nova terra, como

3 A História cultural tem avançado nos últimos anos, com pesquisas que propõem novas fontes, novas indagações e novas metodologias. Essa pluralidade enriquece o debate dos conceitos e traz à luz temas antes inimagináveis, com isso, as discussões historiográficas se renovam. também imagens construtoras da urbe colonial. Acreditamos existir um laço tênue que pode ser fortalecido entre a história da imagem/história da arte $^{4}$ e a história da educação: "a imagem está no âmbito contemporâneo dos debates, pois nossa sociedade é constituída também por esse recurso visual" (KNAUSS, 2008, p. 151). Para ratificar o nosso pensamento de unir imagem, arte e educação, citamos o professor Rafael Cardoso com um trecho do seu texto "A história da arte e outras histórias":

A história da arte é hoje uma área de sólidos fundamentos teóricos e com uma base empírica de estudos em constante expansão. É um campo vibrante e rico, conectado cada vez mais ao pensamento avançado em áreas de suma importância para os dias de hoje como cultura visual, mídias eletrônicas, filosofia da linguagem, teoria da informação, educação. A decodificação minuciosa de imagens e objetos talvez seja a maior contribuição a ser difundida da história da arte para outras áreas de conhecimento, pois se trata de algo do qual nos ocupamos coletivamente há pelo menos dois séculos. (CARDOSO, 2009, p. 113)

Decodificar as imagens é trazer sentido à história, é entender o corpo social ao nosso redor. A arte é extremamente poderosa em representar nas suas entrelinhas os códigos humanos como os conceitos de história, educação, religião, política, cidade e cultura, cabe aos pesquisadores provocar, indagar e não se conformar com o exposto no "primeiro plano". Devemos ir além, quebrar as fronteiras do conhecido, problematizar os contextos históricos

4 Para acrescentar a discussão realizada nessas linhas, citamos o historiador da arte Ernst Hans Gombrich, nome muito conhecido de uma bibliografia clássica sobre estudos da arte nos séculos XX em seu livro "Arte e ilusão" (WMF Martins Fontes). "(...), a história da arte Ocidental foi atacada recentemente com base no argumento de que a noção toda de mimese (a imitação da natureza), de fidelidade à natureza, é uma miragem, um erro grosseiro. Nunca houve imagem que fosse igual à natureza; todas as imagens baseiam-se em convenções, tal como a linguagem ou as letras do alfabeto." (2007, p. 15). 
e perceber que a imagem é fundamental para codificar o mundo.

A proposta desenvolvida aqui pretende analisar pinturas religiosas ${ }^{5}$, sejam cenas da vida dos santos, cenas do evangelho, ou mesmo pinturas que mostrem a catequização promovida pelos religiosos aos povos nativos na América portuguesa. Ainda serão analisadas e problematizadas esculturas e retratos de santos e doutores da igreja Católica, esses responsáveis pela autoridade e representantes do bom comportamento e do bom cristão. Vamos ainda analisar textos literários escritos por religiosos que tragam representações do contexto social e cultural na cidade de São Paulo no final do século XVIII e início do século XIX.

Quando afirmamos que as imagens tomam "vida própria", queremos dizer que, durante a empresa de colonização da América portuguesa, os padres católicos, em suas missões religiosas, fosse no Norte ou no Sul da colônia, utilizavam largamente da arte como estratégia para alcançar o sucesso na catequização dos índios, e na construção de uma cidade barroca, a função das imagens era introduzir o fiel na história e nos mistérios do catolicismo e estimular a devoção, ensinando sobre os passos de Jesus Cristo e da virgem Maria, e proferindo a nova fé no novo espaço, ou seja, estavam criando urbes, novas cidades, novos espaços a partir do barroco. Mas advertimos que essas imagens são apenas uma (parte da) visão, um modelo criado a serviço dos interesses das congregações religiosas que atuavam no Novo Mundo, ou seja, estavam a serviço de uma administração colonial portuguesa e, acima de tudo, religiosa.

A nossa sociedade desenvolve sua sociabilidade a partir das imagens. Somos a todo o momento bombardeados por essa mídia. São imagens audiovisuais (tais como o cinema, a TV, o teatro e a Internet), mas também imagens que podemos encontrar nos museus e igrejas

5 "As pinturas religiosas representam uma espécie de enciclopédia da iconografia católica e uma triunfante defesa da validade das imagens sagradas na prática da fé" (BROWN, 2001, p. 52). barrocas, tais como estátuas, quadros, pinturas, textos e símbolos. A nossa sociedade caracteriza-se como um variado ambiente midiáticoㅇ.

Tomando como base esse ambiente criativo de temas, cores, texturas, textos (leituras), e realizando nele um recorte temporal, vamos privilegiar, neste trabalho, a produção artística do Padre Jesuíno do Monte Carmelo. Além de padre, era artista e trabalhou para muitas paróquias da capitania de São Paulo7. Ele pintou, esculpiu e escreveu músicas; esse personagem está inserido dentro de um mundo barroco, uma sociedade que queria mostrar poder por meio de suas construções religiosas, que reformava e construía novos espaços sagrados, igrejas e templos religiosos para uma comunidade barroca ${ }^{8}$. Sendo assim, vamos realizar um recorte e analisar as duas séries de retratos realizadas pelo Padre Jesuíno. Esses trabalhos encontram-se, atualmente, expostos no Museu de Arte Sacra de São Paulo. Para um pensador dos estudos da imagem como Jacques Aumont, ele nos informa:

\begin{abstract}
É banal falar de "civilização da imagem", mas essa expressão revela bem o sentimento generalizado de se viver em um mundo onde as imagens são cada vez mais numerosas, mas também cada vez mais diversificadas e mais intercambiáveis. (1993, p. 14)
\end{abstract}

6 O professor Paulo Knauss faz um esforço ao estudar a cultura visual e tenta institucionalizar os estudos visuais a partir da afirmação do conceito de cultura visual, elaborado no universo acadêmico dos Estados Unidos. O autor afirma: "Não se pode deixar de reconhecer o potencial de comunicação universal das imagens (...). A imagem é capaz de atingir todas as camadas sociais ao ultrapassar as diversas fronteiras sociais pelo alcance do sentido humano da visão." (2006, p. 99).

7 Entendemos o espaço colonial dentro de uma dinâmica colonialista ibérica portuguesa, sendo uma parte administrativa do mundo atlântico, a América portuguesa é tomada, nesta pesquisa, como uma questão metodológica para problematizarmos e buscarmos entender a diversidade social e a fragmentação do território, pois não podemos pensar em um Brasil colonial como totalidade porque corremos o risco de "cair" em anacronismo.

8 De norte ao sul da colônia, muitos espaços sociais foram fundados em vilas e cidades, fossem no sertão ou no litoral, inúmeros religiosos lançaram mão das imagens barrocas para ajudar na empreitada de educar homens e mulheres aqui na colônia. 
Tomando como base a perspectiva de Aumont, os historiadores fazem História imersos nos arquivos, analisando a documentação, dessa forma, produzimos a ciência historiográfica, e os documentos não escritos, a partir da Nova História, tomaram significados e ajudam a interpretar tempos passados. Representações pictóricas, como as propostas aqui, tornam-se documentos passíveis de análise, interessando à pesquisa histórica?.

O presente trabalho pretende problematizar duas séries de retratos - Doutores da Igreja e Evangelistas da Igreja - pintadas pelo Padre Jesuíno do Monte $\mathrm{Carmel}^{10}$. As imagens mostram personagens importantes para o cristianismo ocidental, como São Boaventura, Santo Tomás, Santo Agostinho, São Gregório Papa, Santo Ambrósio, São Jerônimo, e os Evangelistas São Mateus, São Lucas, São Marcos e São João, essas entidades foram representadas por Jesuíno em seus afazeres cotidianos, na intimidade dos seus estudos e reflexão da filosofia cristã. Assim, podemos problematizar essa obra dentro da cidade de São Paulo, pois esse espaço estava em construção ou atualização social do espaço, era um lugar com sentidos e vivências sociais concedidos por homens, a cidade "é uma construção imaginária do mundo, comporta um conteúdo de ficção, que implica em escolhas, seleção, criatividade, negação, mas que qualifica e confere significação à realidade e se legitima pela credibilidade" (PESAVENTO, 2004, p. 1-2). Vamos analisar esses retratos barrocos com a finalidade de entendê-los como recursos didáticos no ensino e catequização dos índios durante o período colonial na cidade de São Paulo.

A metodologia" empregada nesta pesquisa utilizará como fonte histórica as imagens bar-

9 “(...) a imagem é um componente de grande destaque, mesmo que nem sempre seja valorizada como fonte de pesquisa pelos próprios profissionais da História. A imagem condensa a visão comum que se tem do passado" (KNAUSS, 2006, p. 98-99).

10 Nascido na cidade de Santos-SP, em 1764.

11 Jörn Rüsen, no Capítulo 2 do texto "Reconstrução do Passado", vai mostrar que a metodologia são as regras para a pesquisa histórica, como proceder durante o rocas, tais como: pinturas, esculturas e textos que representem a cultura visual barroca de fins do século XVIII e a primeira metade do século XIX. Vamos privilegiar como objeto de pesquisa as imagens barrocas representativas na ação catequética realizada pelos religiosos cristãos, pois entendemos que essas imagens narram a cultura social e religiosa ocidental na cidade de São Paulo.

Nessa perspectiva, a metodologia empregada nesta pesquisa tomará "emprestado" dos estudos da história da arte a análise de imagens ${ }^{12}$, este método bastante utilizado por pesquisadores da história da arte há anos. Vamos, assim, problematizar e confrontar fontes imagéticas e fontes textuais do período colonial na busca de compreendermos o passado da urbe paulista e educação na América portuguesa ${ }^{13}$.

O recorte temporal escolhido são os anos de produção artística do Padre Jesuíno do Monte Carmelo (1774-1819), sua ampla atuação na produção de peças barrocas com finalidade decorativa para as igrejas das cidades paulistas, e isso inclui a cidade de São Paulo em fins do século XVIII e início do século XIX, são de extrema valia para entendermos o conjunto social e urbanístico do espaço estudado. Nesse período, vamos estudar as mudanças na cultura indígena e a influência das imagens barrocas na ocidentalização ou mesmo no processo civilizador de São Paulo ${ }^{14}$.

trabalho histórico: "O conhecimento dessas regras e sua competência para as empregar na prática definiram e definem o historiador como especialista." Ou "A pesquisa é o trabalho de responder empiricamente às perguntas históricas." (2007, p. 101-105).

12 Para saber mais sobre o método da análise de imagens, ver o trabalho icônico do pesquisador Erwin Panofsky "Significado nas artes visuais", Editora Perspectiva, 2001.

13 "A nós, historiadores, cabe utilizar as ferramentas adequadas para localizar as fontes e saber fazer-lhes perguntas." (FONSECA, 2009, p. 120).

14 O século XVIII ainda é o tempo de adaptação e colonização dos povos indígenas e do seu imaginário por parte dos poderes político e religioso da Metrópole portuguesa, era necessário ensinar a fé cristã ou mesmo impor os códigos culturais religiosos do cristianismo ao outro; desse confronto de culturas surgem tensões e relações de poder que serão estudados e discutidos na tese a partir da documentação imagética e escrita. 


\section{Conclusão}

Do que foi exposto, podemos salientar o quanto é importante o trabalho com fontes pictóricas ou iconográficas, pois ali estão expostos símbolos religiosos, as histórias da vida dos santos, a vida de Maria e de Jesus nos espaços naturais e sociais do velho mundo. Utilizaremos as imagens barrocas com o valioso auxílio das narrações textuais encontradas nos documentos primários dos arquivos do estado de São Paulo e nas cidades de Santos, Itu, São Paulo e Rio de Janeiro.

Entendemos que a iconografia é uma aliada, é a outra metade, faz junção e se completa a outras fontes primárias, serve para explicar e dar sentido ao texto escrito, e vice-versa, sendo essa uma das nossas preocupações na problematização da presente pesquisa ${ }^{15}$.

Queremos pensar, nessa perspectiva, as imagens religiosas barrocas como irradiadoras de sentido, seja por meio da narração visual ou textual, que confere sentido ao corpo social na São Paulo colonial. Para tanto, as perguntas que nos chegam são: Como essas imagens são utilizadas pelos religiosos na cidade de São Paulo? Quais foram as experiências vividas por religiosos e índios durante a catequese na urbe paulistana? Como as imagens barrocas contribuem para uma construção/reelaboração da cidade? Quais os sentidos e ensinamentos que essas imagens barrocas passavam para a sociedade colonial? Que tipo de informações (conceitos) podemos analisar/pensar (extrair) a partir dos retratos pintados pelo Padre Jesuíno do Monte Carmelo?

A intenção deste trabalho é usar a iconografia como documento e problematizar essa fonte como produtora de sentido no espaço urbano colonial. O espaço é visível e dizível onde acontecem as práticas humanas; o espaço é palco das práticas de homens e mulheres, é o

15 Segundo Knauss: "A convivência entre expressão visual e expressão escrita sempre foi muito próxima. Ao longo da história das civilizações, são inúmeros os exemplos em que se percebe como os registros escritos acompanham os registros visuais" (p. 99, 2006). ser humano quem confere sentido aos espaços, construindo-os, trabalhando-os, criando-os, formatando, ensinando e transformando ${ }^{16}$.

Buscaremos entender essas imagens em seus usos pedagógicos, utilizadas pelos padres jesuítas e franciscanos na educação formal e religiosa dos índios ${ }^{17}$, como também a influência da arte barroca na formação urbana da São Paulo colonial. Vamos buscar compreender a invenção dos novos espaços urbanos e sociais, ou seja, o processo de ocidentalização cultural por meio das imagens.

Entendemos que a arte religiosa é um recorte, é uma escolha, é uma construção, sendo assim, as imagens são testemunhos da eficácia didática da educação religiosa, a arte é intercessora entre o divino e o humano, ela modela as condutas no convívio social.

\section{Referências}

ALMEIDA, L. M. de. A sacralização dos trópicos. In: Arte Sacra de Alagoas: um tesouro da memória. Brasília: Senado Federal, 2013.

ALLOA, E. (org.). Pensar a imagem. 1. ed. Belo Horizonte: Autêntica Editora, 2007.

ANDRADE, M. de. Padre Jesuíno do Monte Carmelo. Rio de Janeiro: Nova Fronteira, 2012.

ARGAN, G. C. Imagem e persuasão: ensaios sobre o barroco. São Paulo: Cia. das Letras, 2004.

16 Nesse sentido, as imagens têm o poder dos discursos na construção dos espaços. Segundo Raimundo Arrais: o espaço não tem uma natureza cristalizada, não está impregnado de uma essência prévia. Seus significados derivam dos investimentos simbólicos feitos sobre ele, por meio de rituais promovidos pelo Estado ou certos grupos sociais (...), não há espaço sem as práticas que lhe confere sentido (2004, p. 15)

17 O índio e as comunidades indígenas serão nosso principal foco de interesse e estudo nesta pesquisa, no entanto, a história cultural aponta que não foram apenas os povos nativos que passaram pelo processo de catequização e colonização do imaginário. Aqui na América outras comunidades, tais como: negros escravos, negros livres, brancos pobres, mestiços, marginalizados e subalternos do período colonial, também foram influenciados pelas imagens barrocas e a pedagogia praticada pelos padres jesuitas. 
AUMONT, J. A imagem. Trad. Estela dos S. Abreu e Cláudia C. Santoro. Campinas, SP: Papirus, 1993.

BARSALINI, M. S. I. Mário e Jesuíno nos caminhos de um texto. In: ANDRADE, M. de. Padre Jesuíno do Monte Carmelo. Rio de Janeiro: Nova Fronteira, 2012.

BROWN, J. Pintura na Espanha 1500-1700. Trad. Luiz Antônio Araújo. São Paulo: Cosac \& Naify Edições, 2001.

FONSECA, T. N. de L. Historiografia da educação na América portuguesa: balanço e perspectivas. Revista Lusófona de Educação, 2009.

KNAUSS, P. O desafio de fazer História com imagens: arte e cultura visual. ArtCultura, Uberlândia, v. 8, n. 12, p. 97-115, jan./jun. 2006.
PANOFSKY, E. Iconografia e Iconologia: uma introdução ao estudo da arte da Renascença. Significado nas Artes Visuais. São Paulo: Perspectiva, 2001.

PESAVENTO, S. J. A invenção do Brasil: o nascimento da paisagem brasileira sob o olhar do outro. Fênix - revista de história e estudos culturais, v. 1, ano 1, n. 1, out./nov./dez. 2004.

Um encontro marcado - e imaginário - entre Gilberto Freyre e Albert Eckhout. Fênix Revista de História e Estudos Culturais, v. 3, ano 3, n. 2, abr./mai./jun. 2006.

TORRÃO FILHO, A. Paradigma do caos ou cidade da conversão?: São Paulo na administração do Morgado de Mateus (1765-1775). São Paulo: Annablume; FAPESP, 2007. 
